\title{
Identification and key management of non-transfusion-dependent thalassaemia patients: not a rare but potentially under-recognised condition
}

Vip Viprakasit ${ }^{{ }^{*}}$, Paul Tyan², Sarayuth Rodmai ${ }^{1}$ and Ali T Taher ${ }^{2^{*}}$

\begin{abstract}
Patients with non-transfusion-dependent thalassaemia (NTDT) have a genetic defect or combination of defects that affect haemoglobin synthesis, but which is not severe enough to require regular blood transfusions. The carrier frequency of NTDT is high (up to $80 \%$ in some parts of the world) but the prevalence of symptomatic patients varies with geography and is estimated to be from 1 in 100,000 to 1 in 100. NTDT has a variable presentation that may include mild to severe anaemia, enlarged spleen and/or liver, skeletal deformities, growth retardation, elevated serum ferritin and iron overload. The contributing factors to disease progression are ineffective erythropoiesis and increased haemolysis, which lead to chronic anaemia. The body's attempts to correct the anaemia result in constantly activated erythropoiesis, leading to marrow expansion and extramedullary haematopoiesis. Diagnosis of NTDT is largely clinical but can be confirmed by genetic sequencing. NTDT must be differentiated from other anaemias including sideroblastic anaemia, paroxysmal nocturnal haemoglobinuria, congenital dyserythropoietic anaemia, myelodysplastic syndromes and iron-deficiency anaemia. Management of NTDT is based on managing symptoms, and includes blood transfusions, hydroxyurea treatment, iron chelation and sometimes splenectomy. Prognosis for well managed patients is good, with most patients living a normal life. Since NTDT is mainly prevalent in sub-tropical regions, patients who present in other parts of the world, in particular the Northern hemisphere, might not been correctly recognised and it can be considered a 'rare' condition. It is particularly important to identify and diagnose patients early, thereby preventing complications.
\end{abstract}

Keywords: Non-transfusion-dependent thalassaemia, Thalassaemia intermedia, $\mathrm{HbE}$ disease, $\mathrm{HbH}$ disease, Iron chelation, RBC transfusion, Hydroxyurea

\section{Model case study}

A 9-year old girl of South East Asian origin undergoes routine medical check-up by her local physician. The parents had noted that the child is lethargic and that she reaches her development milestones slightly late. She is short for her age, although not quite below the fifth percentile line of the growth chart. Clinical examination shows mild scleral icterus, tachycardia with regular rhythm, II/VI

\footnotetext{
* Correspondence: vip.vip@mahidol.ac.th; ataher@aub.edu.lb
'Department of Pediatrics and Thalassemia Center, Faculty of Medicine, Siriraj

* Correspondence: vip.vip@mahidol.ac.th; ataher@aub.edu.lb
'Department of Pediatrics and Thalassemia Center, Faculty of Medicine, Siriraj Hospital, Mahidol University, Bangkok 10700, Thailand ${ }^{2}$ Hematology and Oncology, Department of Internal Medicine, American
University of Beirut Medical Center, PO Box 11-0236, Riad El Solh 11072020 ${ }^{2}$ Hematology and Oncology, Department of Internal Medicine, American
University of Beirut Medical Center, PO Box 11-0236, Riad El Solh 11072020 Beirut, Lebanon
}

(c) 2014 Viprakasit et al.; licensee BioMed Central Ltd. This is an Open Access article distributed under the terms of the Creative Commons Attribution License (http://creativecommons.org/licenses/by/2.0), which permits unrestricted use, distribution, and reproduction in any medium, provided the original work is properly credited. The Creative Commons Public Domain Dedication waiver (http://creativecommons.org/publicdomain/zero/1.0/) applies to the data made available in this article, unless otherwise stated.

flow murmur over the left sternal border and mild hepatosplenomegaly. Laboratory test results (normal values) were as follows: serum ferritin, $321 \mathrm{ng} / \mathrm{mL}(6-24 \mathrm{ng} / \mathrm{mL})$; iron $155 \mu \mathrm{g} / \mathrm{dL}(50-120 \mu \mathrm{g} / \mathrm{dL})$; haemoglobin $(\mathrm{Hb}), 8.1 \mathrm{~g} / \mathrm{dL}$ (11-16 g/dL); Chem-10 $10^{1}$ within normal limits; total bilirubin $3.4 \mathrm{mg} / \mathrm{dL}(0-1.5 \mathrm{mg} / \mathrm{dL})$. The blood smear shows mild microcytic anaemia (mean corpuscular volume [MCV] $64 \mathrm{fL}[70-86 \mathrm{fL}]$, mean corpuscular $\mathrm{Hb}[\mathrm{MCH}]$ $19.5 \mathrm{pg}$ [28-32 pg], mean corpuscular Hb concentration [MCHC] $28.5 \mathrm{~g} / \mathrm{dL}$ [11.5-13.5 g/dL], RBC distribution $27.9 \%$ [11.5-14.5\%]) and reticulocyte count $8 \%$. There is no evidence of inclusion bodies, but the dichlorophenolindophenol (DCIP) precipitate test is positive. Hb electrophoresis test finds $\mathrm{HbE} 45 \%$ with $\mathrm{HbF} 55 \%$. She is diagnosed 
with $\mathrm{HbE} / \beta$-thalassaemia disease and referred to a specialist for long-term management. A haematologist classifies her as having non-transfusion-dependent thalassaemia (NTDT) and recommends intermittent blood transfusions to overcome growth retardation, vigilant observation during periods of infection for the development of acute haemolysis and annual monitoring of body iron levels from age 10 years onwards, with treatment as required.

\section{An introduction to non-transfusion-dependent thalassaemia \\ Definition}

Non-transfusion-dependent thalassaemia (NTDT) describes patients who have an inherited genetic defect or combination of defects that affect $\mathrm{Hb}$ chain synthesis and, consequently, the oxygen-carrying capacity of red blood cells [1-4]. NTDT is a broad term that covers several thalassaemia disorders, including $\mathrm{HbH}$ disease (ORPHA93616), $\beta$-thalassaemia intermedia (ORPHA231222), and HbE/ $\beta$-thalassaemia (ORPHA231249). Even though NTDT patients are often anaemic, they do not rely on blood transfusions for daily function and survival, which differentiates them from patients with thalassaemia major (TM) or transfusion-dependent thalassaemia (TDT). However, abnormal RBC synthesis can cause debilitating clinical symptoms that impact morbidity, quality of life and mortality [4-8]. The transfusion requirements of a NTDT patient can change over time and there is also considerable variability between the transfusion needs of different individuals [7]. The patient described in the case study fits the definition of NTDT, because she is not reliant on blood transfusions for daily function and survival. Nevertheless, the symptoms of growth retardation indicate a need for treatment.

\section{Genetics and epidemiology of NTDT}

Genetic defects that affect the synthesis of globin chains can be divided into two broad groups: 1) a defect(s) in one or more of the genes that code for $\beta$-globin chain, 2) a defect(s) in one or more of the genes that code for $\alpha$-globin chain [5-7]. To date, more than 300 different thalassaemia defects of the globin chains have been discovered and these can be further classified according to their type, i.e., insertion, deletion or base substitution $[5-7,9]$.

$\beta$-thalassaemia, which results from one or more defects in the genes that code for the $\beta$-globin chain, or $\alpha$-globin gene rearrangements causing duplication, has 80 to 90 million carriers worldwide (1.5\% of the global population) [5]. The highest prevalence is found in India, Bangladesh and South East Asia (where the carrier frequency is approximately $1-5 \%)[8,10,11]$. One $\beta$-globin gene defect that is highly prevalent in this population is a singlepoint mutation (HBB:c.79G > A) causing Haemoglobin $\mathrm{E}(\mathrm{HbE})[5]$.
In the past, $\alpha$ - and $\beta$-thalassaemias were restricted to malaria-endemic tropical and subtropical regions $[6,12,13]$. However, in recent years, human global migration from these regions has caused an increase in these conditions in countries previously relatively unaffected by thalassaemias, such as those in North Europe and North America $[6,12,13]$. Therefore, thalassaemia syndromes are no longer 'rare' conditions in such regions and warrant awareness from all health care providers involved. The genotypes and phenotypes of thalassaemia are shown in Table 1.

An estimated 300,000 children are born each year with a genetic defect of one or more genes that code for $\alpha / \beta$-globin chains [4]. If the $\operatorname{defect}(s)$ affect(s) the expression of two corresponding $\alpha$ - or $\beta$-globin genes, then phenotypic thalassaemia develops [4].

The clinical course of thalassaemia varies greatly and depends on the combination of genetic anomalies in a patient $[14,15]$. People with deleterious genetic defects on both alleles coding for $\beta$-globins develop the most severe form of $\beta$-thalassaemia, namely $\beta$-thalassaemia major. The most severe form of $\alpha$-thalassaemia is hydrops foetalis with $\mathrm{Hb}$ Barts, a fatal disorder that results from genetic deletions that abolish the expression of all $\alpha$ genes. Genetic defects other than those resulting in $\beta$-thalassaemia major and hydrops foetalis encompass a wide spectrum of severity, from asymptomatic to mild and from moderately severe to severe. The severity of a thalassaemic disorder is associated with the extent of anaemia and consequently the need for therapeutic strategies to overcome anaemia. So, patients with a severe thalassaemia, such as $\beta$-thalassaemia major, develop debilitating anaemia and are transfusion dependent. Patients with milder forms of thalassaemia, such as $\beta$-thalassaemia intermedia, $\mathrm{HbE}$, and $\mathrm{HbH}$ disease develop anaemia, but it is not so severe that they are dependent on RBC transfusions for survival. This group of patients is therefore considered to have NTDT [1-7].

\section{Pathophysiology of NTDT}

The main drivers underlying the pathophysiology of NTDT are chronic anaemia; ineffective erythropoiesis and chronic haemolysis from peripheral destruction of RBCs; and compensatory physiological mechanisms that attempt to rectify a state of anaemia, including marrow expansion, extramedullary haematopoiesis and increased absorption of gastrointestinal iron. Because these mechanisms cannot overcome the genetic defect in synthesizing fully functional RBCs, they are constantly activated, leading to the development of diverse clinical complications (see Figure 1) [5-7,16-20]. The ways in which the main pathophysiological drivers of NTDT mediate clinical complications are explained below. 
Table 1 Genotypes and phenotypes of thalassaemia

\begin{tabular}{|c|c|c|c|}
\hline & Variant & Genotype & Phenotype \\
\hline \multirow{5}{*}{ a-thalassaemia } & Normal & $a a / a a$ & Normal \\
\hline & Silent Carrier & $-a / a a$ & Haematologically silent or mild reduction of $\mathrm{MCH} / \mathrm{MCV}$ \\
\hline & Minor & $-a /-a,--/ a a$ & $\begin{array}{l}\text { Borderline anaemia or normal, as well as microcytic } \\
\text { and hypochromic red blood cells }\end{array}$ \\
\hline & $\mathrm{HbH}$ disease* & $--/-a,--/ a^{\top} a, a^{\top} a / a^{\top} a$ & $\begin{array}{l}\text { Majority have mild to moderate anaemia and } \\
\text { marked microcytosis and hypochromia, only few } \\
\text { have phenotype similar to thalassaemia major }\end{array}$ \\
\hline & Barts Hydrops Foetalis & $--/--$ & $\begin{array}{l}\text { Most develop hydrops foetalis syndrome and die } \\
\text { in utero, or shortly after birth }\end{array}$ \\
\hline \multirow{4}{*}{$\beta$-thalassaemia } & Normal & $\beta / \beta$ & Normal \\
\hline & Minor & $\beta / \beta^{+}, \beta / \beta^{0}$ & $\begin{array}{l}\text { Borderline anaemia or normal as well as microcytic } \\
\text { and hypochromic red blood cells }\end{array}$ \\
\hline & $\beta$-thalassaemia intermedia* & $\beta^{+} / \beta^{+}, \beta^{0} / \beta^{+}, \beta^{+} / \beta, \beta^{0} / \beta, \beta^{0} / \beta^{0}$ & $\begin{array}{l}\text { Severity is very variable. Clinical picture ranges } \\
\text { from mild to moderate NTDT }\end{array}$ \\
\hline & Major & $\beta^{0} \beta^{0}, \beta^{0} / \beta^{+}$ & Severe anaemia requiring regular transfusions (TDT) \\
\hline \multirow{4}{*}{$\mathrm{HbE}$} & HbE trait & $\beta^{\mathrm{E}} / \beta$ & Asymptomatic condition with no clinical relevance \\
\hline & Homozygous HbE & $\beta^{E} / \beta^{E}$ & $\begin{array}{l}\text { Usually asymptomatic with borderline asymptomatic } \\
\text { anaemia and no haemolysis }\end{array}$ \\
\hline & $\mathrm{HbE} / \beta$-thalassaemia* & $\beta^{E} / \beta^{+}, \beta^{E} / \beta^{0}$ & $\begin{array}{l}\text { Severity is very variable. Clinical picture ranges } \\
\text { from NTDT to TDT }\end{array}$ \\
\hline & $\mathrm{HbE} / \mathrm{HbS}$ & $\beta^{E} / \beta^{S}$ & $\begin{array}{l}\text { Similar to sickle cell disease usually with rare } \\
\text { vaso-occlusive crisis }\end{array}$ \\
\hline
\end{tabular}

*Thalassaemia genotypes that often result in NTDT.

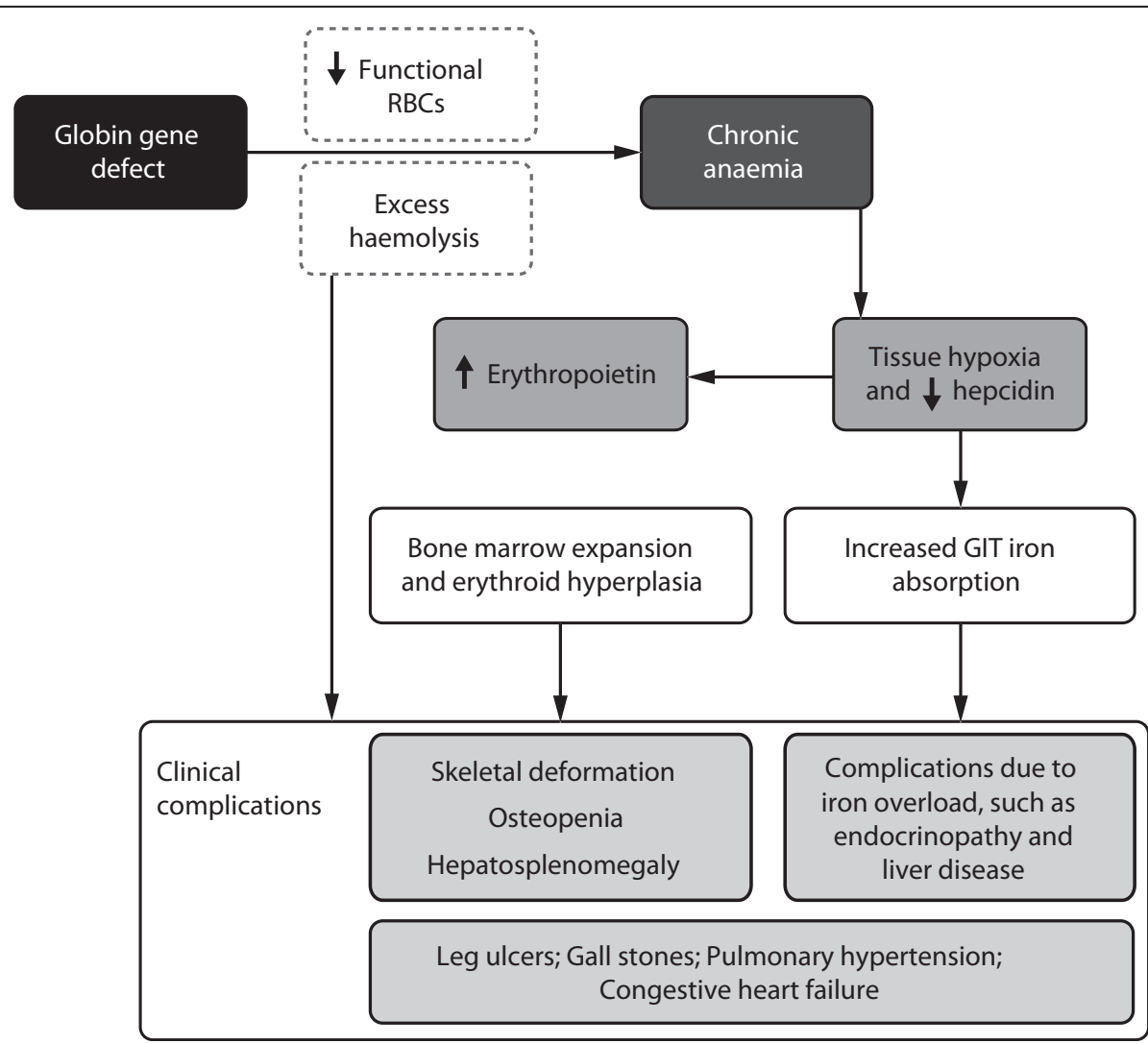

Figure 1 The pathophysiology of clinical complications of NTDT. 


\section{Chronic anaemia}

NTDT patients have underlying anaemia with $\mathrm{Hb}$ levels varying between 7-11 g/dL [18,20,21]. Due to imbalances in $\alpha$ - and $\beta$-globin chains, globin tetramers are unstable resulting in precipitation and degradation. This process releases free iron and leads to the formation of reactive oxygen species, causing membrane damage and ultimately premature cell death in bone marrow (ineffective erythropoiesis) or peripheral circulation (haemolysis) [22,23]. The severity of anaemia is determined by both the extent of ineffective erythropoiesis and the extent of haemolysis [24]. Haemolysis is associated with progressive splenomegaly and can also contribute to a hypercoagulable state, which many NTDT patients experience. Anaemia can be severe and life-threatening in NTDT patients who experience a physiological challenge, such as illness, trauma or pregnancy; and can also cause growth failure and delayed development $[25,26]$. The patient described in our case study clearly had growth failure; this is most likely to be a result of chronic anaemia. Her $\mathrm{Hb}$ level at the time of presentation was $8.1 \mathrm{~g} / \mathrm{dL}$ (reference range: $11-16 \mathrm{~g} / \mathrm{dL}$ ).

\section{Ineffective erythropoiesis}

Normal physiological compensation for anaemia is an increase in erythropoietin (EPO) from renal interstitial fibroblasts and hepatic perisinusoidal cells. In thalassaemia, the desired outcome of an increase in functional circulating RBCs is unattainable and EPO stimulation is therefore constantly upregulated [24]. Constant elevation of EPO levels drives erythroid marrow expansion and the development of extramedullary erythroid tissue in the chest, abdomen and pelvis, causing skeletal deformities and osteopenia [27-29]. The inherently defective erythropoiesis in thalassaemia inhibits the differentiation of early erythroid progenitors, resulting in large numbers of these progenitor cells in the liver and spleen. This, together with the excessive amounts of damaged RBCs that are filtered by the spleen, leads to hepatosplenomegaly [24].

\section{Iron overload}

In NTDT, iron uptake from the gastrointestinal tract (GIT) is considerably higher than normal because the upregulated rate of erythropoiesis sequesters large amounts of physiological iron [30]. However, as the sequestered iron is not incorporated into fully functional RBCs, transferrin levels become saturated and unbound physiological iron is deposited in organs, especially the liver. The serum ferritin levels in our case study patient were considerably higher than normal (321 ng/mL compared with the reference range of 30-150 ng/mL), despite her having no history of $\mathrm{RBC}$ transfusion. In addition, iron absorption through the gut can be increased due to reduction of hepcidin production in NTDT patients. Hepcidin negatively regulates both duodenal iron absorption and macrophage iron release. Hepcidin binds ferroportin on cells of the intestinal duodenum, macrophages, and cells of the placenta, inducing internalization and degradation. In thalassaemia, overexpression of the erythropoietic factor, growth differentiation factor 15 (GDF15) contributes to iron overload by inhibiting hepcidin expression, and thereby increasing iron absorption through the gut [31,32]. The serum ferritin levels in our case study patient illustrates how extensive iron uptake from the GIT can be in patients with $\mathrm{HbE} / \beta$-thalassaemia $[31,32]$.

\section{Other complicating factors}

In addition to anaemia, ineffective erythropoiesis and iron overload, several molecular and cellular mechanisms that play a part in the regulation of blood coagulability are dysregulated in NTDT. In these patients, chronic platelet activation, dysregulation of adhesion molecules on vascular endothelial cells and abnormal RBC membranes contribute to a state of hypercoagulability, which increases the risk of thromboembolic complications $[33,34]$.

\section{Clinical characteristics and common complications of NTDT patients}

The clinical characteristics of NTDT patients are associated with the severity of chronic anaemia and all NTDT patients are at risk of developing a wide variety of clinical complications including gallstones, leg ulcers, growth retardation, pulmonary hypertension (PHT), splenomegaly, liver disease and thromboembolic events [16,17,19-21,29,34]. The risks of developing many of these complications are known to increase with age $[16,26]$. Table 2 lists the most common complications and their prevalence in the different types of thalassaemia associated with NTDT. It is important to note that many patients with NTDT may go undiagnosed, and therefore the frequency of the complications listed are more reflective of those patients with moderate-to-severe NTDT phenotypes.

\section{$\beta$-thalassaemia intermedia}

Patients with $\beta$-thalassaemia intermedia usually present when they are $\geq 2$ years of age and their $\mathrm{Hb}$ level normally lies between 7-10 g/dL [20]. They are generally considered non-transfusion dependent, but at the more severe end of the spectrum, this may not be the case. Children with $\mathrm{Hb}$ levels in the range of $5-6 \mathrm{~g} / \mathrm{dL}$ often develop skeletal deformities. Patients with $\mathrm{Hb}$ levels in the range of 6-9 g/dL develop normally, but they are prone to progressive splenomegaly and declining $\mathrm{Hb}$ levels later in life, or when physiological stressors such as infection or pregnancy complicate their condition. $\beta$-thalassaemia intermedia patients have an increased susceptibility to infections and skeletal changes and they require individualized treatment strategies because their 
Table 2 Characteristics and complications in NTDT patients* [5, 16,20,35-41]

\begin{tabular}{llll}
\hline Characteristics and complications & $\beta$-thalassaemia intermedia & HbE/ $\beta$-thalassaemia & a-thalassaemia syndromes ${ }^{\ddagger}$ \\
\hline Presenting age (years) & Usually $>2$ & Usually $>2$ & Usually $>2$ \\
Presenting Hb level (g/dL) & $7-10$ & $9-12$ (mild) & $8-11$ \\
HbF(\%) & $3-50$, but can be up to 100 & $3-7$ (moderately severe) & Not raised, but HbH $\left(\beta_{4}\right)$ \\
and Hb Barts $\left(\gamma_{4}\right)$ present
\end{tabular}

*Viprakasit V, unpublished data.

${ }^{\ddagger} \mathrm{a}$-thalassaemia syndromes include deletional $\mathrm{HbH}$ and non-deletional $\mathrm{HbH}$ disease.

Frequency of complications are expressed as:

0-10\%: +

10-30\%: ++

$30-60 \%:+++$

60-100\%: ++++

clinical severity lies between $\beta$-thalassaemia major and minor [20]. Management of these patients is particularly challenging for clinicians because they can present with a wide variety of complications which can vary in severity. In addition, until recently there were few clear guidelines on treating the underlying disease (the Thalassaemia International Federation guidelines for the management of NTDT were released recently) [42].

\section{$\mathrm{HbE} / \beta$-thalassaemia}

This disease can be classified into three categories on the basis of clinical severity: mild (observed in 15\% of patients with this disease in South East Asia); moderately severe (represents the majority of $\mathrm{HbE} / \beta$-thalassaemia cases); and severe. It is estimated that up to half of all patients with $\mathrm{HbE} / \beta$-thalassaemia exhibit clinical symptoms resembling those of $\beta$-thalassaemia major, while the remainder bear a clinical resemblance to the phenotype of $\beta$-thalassaemia intermedia or NTDT [35].

\section{$\mathrm{HbH}$ disease}

Patients with $\mathrm{HbH}$ disease can be classified as having either a non-deletional or a deletional defect of the $\alpha$-globin genes. Patients with a non-deletional defect generally have lower levels of $\mathrm{Hb}$ and higher levels of $\mathrm{HbH}$ and inclusion bodies than those who have a deletional defect [36]. Non-deletional $\mathrm{HbH}$ is therefore considered a more severe form of the disease than deletional $\mathrm{HbH}$. In addition, patients with non-deletional $\mathrm{HbH}$ disease were found to have more symptoms at a younger age, more severe haemolytic anaemia, more growth retardation, more dysmorphic facial features, larger spleens, larger livers, and higher serum ferritin levels $[18,36]$. These patients required more transfusions than patients with deletional $\mathrm{HbH}$ disease [18]. All patients with $\mathrm{HbH}$ disease are prone to infections, leg ulcers and gallstones; and those older than 45 years of age are susceptible to iron overload even if they do not receive regular blood transfusions $[6,18,36,43]$. $\mathrm{HbH}$ and $\alpha$-thalassaemia syndrome has been recently reviewed and hence we will not discuss in detail here [44].

\section{Making a diagnosis Identifying NTDT patients}

Many of the clinical complications common in NTDT can be prevented by early intervention strategies. A diagnosis of NTDT before the onset of clinical complications is therefore a valuable investment in the future health of patients. In addition, screening families in high frequency areas may well offer clinical value and will allow for prenatal counselling.

Children with NTDT commonly present with symptoms of anaemia, such as pallor, fatigue, dizziness or vertigo, tachycardia and dyspnoea [36]. Children are usually older than two years of age at the time of presentation 
and those with mild anaemia can present much later [20]. Our case study patient presented with several symptoms of anaemia. Her parents described her as being lethargic, which is a sign of fatigue, and clinical examination revealed pallor (mild scleral icterus) and tachycardia. In addition, this child was nine years of age at the time of presentation, suggesting NTDT rather than $\beta$-thalassaemia major.

NTDT patients with moderately severe phenotype can develop a haemolytic crisis during an acute pathogenic infection or high fever. In a relatively small percentage of these patients, this event triggers investigation into the presence of an underlying haemoglobinopathy. The $\mathrm{Hb}$ levels of NTDT patients experiencing a haemolytic crisis rapidly decline and as a result they can be mistaken for having TDT and erroneously entered into a management programme of lifelong, regular transfusions. It is therefore advised that once children recover from the underlying factor that initiated a haemolytic crisis, transfusion therapy be interrupted so that appropriate baseline $\mathrm{Hb}$ levels can be determined [45]. In our practices, we will follow such cases with monthly complete blood count (CBC) monitoring for at least 6 months to determine their baseline $\mathrm{Hb}$ and associated clinical symptoms such as clinical anaemia, fatigue, lethargy, poor feeding, poor weight gain, intercurrent infection, liver and spleen size and development of bone deformities. These parameters will be carefully considered to categorize patients into either TDT or NTDT phenotypes.

\section{The diagnostic work-up}

The diagnostic protocol for NTDT uses complete blood cell counts with erythrocyte indices as measured by an automated blood cell counter. Typically, blood analyses of almost all thalassaemias show a reduction in the size and $\mathrm{Hb}$ content of mature RBCs, which is evident in a reduced $\mathrm{MCV}$ and mean cell $\mathrm{MCH}$ [46]. Low $\mathrm{MCV}$ $(<80 \mathrm{fl})$ and/or $\mathrm{MCH}(<27 \mathrm{pg})$ require further investigation by means of electrophoresis, high-pressure liquid chromatography (HPLC) and DNA analysis to identify the thalassaemia type and the genetic defects as shown in Figure 2 [46-48]. If NTDT is suspected, family studies are an important aspect of diagnosis.

There are inexpensive screening tests available, but they utilize the reduced osmotic fragility characteristic of the RBCs of thalassaemia and therefore do not always distinguish thalassaemia from iron deficiency anaemias. A short period (up to 3 months) of iron supplementation (4-6 $\mathrm{mg} / \mathrm{kg} /$ day of elemental iron) is recommended in cases with unclear diagnosis. If there is no significant improvement (increased $\mathrm{Hb}, \mathrm{MCV}$ and $\mathrm{MCH}$ values), a further determination for NTDT by Hb and DNA analyses should be pursued. Other causes of anaemia such as sideroblastic anaemia, congenital dyserythropoietic anaemia, paroxysmal nocturnal haemoglobinuria, myelodysplastic syndromes and other anaemias including nutritional anaemias such as megaloblastic anaemia should be considered and differentiated from NTDT patients. Patients with $\beta$-thalassaemia usually have elevated $\mathrm{HbA}_{2}$ (except those with silent $\beta$-thalassaemia defects), therefore, combining the results of 1 ) a test that measures $\mathrm{HbA}_{2}$ level and 2) the results of a full blood count $(\mathrm{MCH}$ and $\mathrm{MCV})$ is an appropriate initial screening test for $\beta$-thalassaemia [4]. Identification of $\alpha$-thalassaemia is more complicated and the only fail-safe assessment is DNA analysis, though inclusion bodies visible in the blood smear is an important indicator $[4,49]$. Figure 2 shows an algorithm for diagnosis of $\alpha$ - and $\beta$-thalassaemia syndromes associated with NTDT phenotype. However, even though NTDT can be defined by genotype, the diagnosis is mainly clinical and it is based on the severity of the patient's condition [20]. Table 3 is a guide to differentiate between TDT and NTDT patients.

\section{An overview of management strategies in NTDT}

Patients with NTDT should be followed by a specialist for long-term management, they should therefore be referred to a haematologist once diagnosed. Long-term therapeutic strategies for NTDT include blood transfusion; hydroxyurea (HU) administration; iron chelation therapy; and splenectomy in cases of severe splenomegaly and/or hypersplenism. Even though specialist haematologists usually manage the long-term therapy of NTDT patients, family physicians should be knowledgeable about the key components of therapy because NTDT patients also seek medical attention for problems that are unrelated to NTDT. The prescription of treatment for medical problems unrelated to NTDT should be done with consideration of the therapeutic strategies that are a part of the long-term management of NTDT.

\section{Blood transfusion therapy}

The initiation of transfusion in NTDT patients can have clinical as well as prophylactic benefits. The OPTIMAL CARE study showed that patients given intermittent or regular transfusions developed fewer clinical complications that are usually linked to chronic anaemia, but they were more prone to develop iron overload-related endocrinopathy [21]. Several observational studies have reported fewer thromboembolic events, PHT and silent brain infarcts in NTDT patients who receive intermittent transfusions versus those who are never transfused [50]. There is also evidence to suggest that the health-related quality of life of NTDT patients is worse than regularly transfused patients [51]. Taher et al. have suggested raising baseline $\mathrm{Hb}$ for NTDT patients to over $9 \mathrm{~g} / \mathrm{dL}$ in order to prevent future complications as a prophylactic measure [52]. Nevertheless, it remains important for practicing physicians to communicate and discuss with their NTDT patients in 


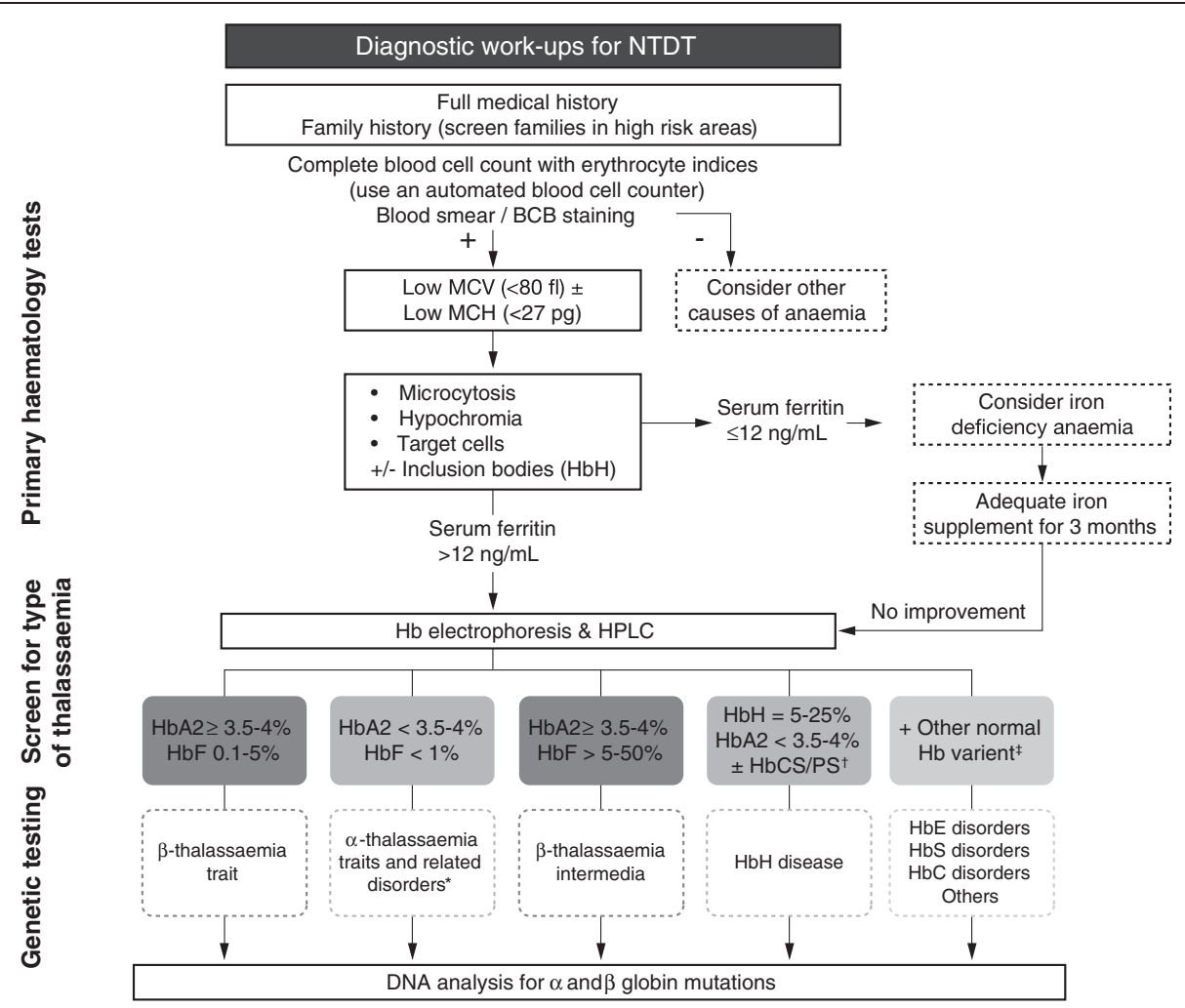

Figure 2 Diagnostic algorithm for NTDT. * $a$-thalassaemia traits and related disorders include $a^{0}$ and $a^{+}$-thalassaemia by deletions and non-deletional a-thalassaemia mutations. ${ }^{\dagger}$ There are two main types of $\mathrm{HbH}$ disease: 1$)$ deletional $\mathrm{HbH}$ due to deletions $(--/-\mathrm{a})$ and; 2) non-deletional $\mathrm{HbH}$ disease caused by $\mathrm{a}^{0}$-thalassaemia and non-deletional mutation $\left(--/ \mathrm{a}^{\top} \mathrm{a}\right) .{ }^{{ }^{\top}}$ The common disorders associated with $\mathrm{Hb}$ variants include homozygous $\mathrm{HbE}, \mathrm{HbE} / \beta$ thalassaemia and $\mathrm{HbE}$ with other variants such as $\mathrm{HbE} / \mathrm{HbS}$ or $\mathrm{HbE} / \mathrm{HbC}$ or $\mathrm{HbE} / \mathrm{HbD}$, $\mathrm{HbS}$ (Sickle), $\mathrm{HbS} / \beta$-thalassaemia, homozygous $\mathrm{HbC}$ and $\mathrm{HbC} / \beta$ thalassaemia. These diagnoses can be confirmed using appropriate globin genotyping.

Table 3 Differentiation between TDT and NTDT

TDT more likely NTDT more likely

\section{Clinical}

Presentation (years)

$\begin{array}{cc}<2 & >2 \\ 6-7 & 8-10\end{array}$

$\mathrm{Hb}$ levels $(\mathrm{g} / \mathrm{dL})$

Severe

Growth retardation/pubertal failure*

Clinical anaemia affecting daily living

$+++/++++$

Yes

Yes

Bone deformity/thalassaemic facie

\section{Haematologic}

Nucleated RBC $\left(\mathrm{mm}^{3}\right)$

Reticulocytosis

\section{Molecular}

Type of globin defects

Co-inheritance of ameliorating genetic modifiers ${ }^{\dagger}$

Co-inheritance of deteriorating genetic modifiers ${ }^{\ddagger}$
Numerous

$\geq 10 \%$ of $\mathrm{RBC}$

Negative to few

$<10 \%$ RBC

Severe

Mild/silent

No

Yes

Yes

No

Modified from Thalassaemia International Federation Guideline (2008 second edition).

${ }^{*}$ Growth retardation; $++, \mathrm{P}<25 \mathrm{P},+++,<10 \mathrm{P}$ and $++++=<3 \mathrm{P}$;

${ }^{\dagger}$ Ameliorating genetic modifiers represent genetic factors that can reduce globin imbalance such as a-thalassaemia and/or quantitative trait loci that increase $\gamma$-globin expression in $\beta$-thalassaemia intermedia or $\mathrm{HbE} / \beta$-thalassaemia, $\beta$-thalassaemia gene in $\mathrm{HbH}$ disease.

${ }^{F}$ Deteriorating genetic modifiers include genetic polymorphisms that can further advance disease severity directly and indirectly such as multiple alpha globin gene rearrangements, genetic haemochromatosis, vitamin D receptor, UGT1A1, a-Hb stabilizing protein polymorphism etc. 
order to tailor their transfusion care to suit the patient's level of compliance and the resource available in their own healthcare service.

\section{Hydroxyurea}

$\mathrm{HU}$, as an inducer of $\mathrm{HbF}$, has been tested in patients with $\beta$-thalassaemia major, $\beta$-thalassaemia intermedia and $\mathrm{HbE} / \beta$-thalassaemia. This compound affects stem cell differentiation in the bone marrow and promotes selective advantages of F-cells and stimulates post-natal expression of $\gamma$-globin genes in order to up-regulate $\mathrm{HbF}$ production. This results in less globin imbalance and reduced ineffective erythropoiesis. However, increases in $\mathrm{Hb}$ after initiation of HU have been shown to vary between $0.6-2.5 \mathrm{~g} / \mathrm{dL}$ and several NTDT patients did not respond at all to HU [53-55]. Evidence suggests that the response to $\mathrm{HU}$ treatment is likely to be dependent on several clinical and genetic factors including Xmn I polymorphism [56,57]. The OPTIMAL CARE study showed that in patients with $\beta$-thalassaemia intermedia, HU has clinical benefit, especially when combined with transfusion and iron chelation therapy [21]. Short- and medium-term administration of $\mathrm{HU}$ was also well tolerated by $\beta$-TI patients, but the effectiveness seems to decline with long-term use [54].

\section{Iron chelation therapy}

It is essential to monitor physiological iron loads in NTDT because of the abnormally high uptake of iron from the GIT in these patients [30,31]. RBC transfusions, given intermittently or on a fairly regular basis, also contribute to systemic iron accumulation.

It is known that NTDT patients develop extensive liver iron loading although their serum ferritin levels are relatively low compared with the serum ferritin levels indicative of liver iron loading in transfusion-dependent patients $[58,59]$. This complicates the monitoring of physiological iron loads in NTDT, because the current thresholds for serum ferritin used to guide chelation therapy in transfusion-dependent patients cannot be extrapolated to NTDT patients. Taher and Viprakasit et al. recently developed a treatment algorithm based on the specific relationship that exists between serum ferritin levels and liver iron concentration in NTDT to guide a decision on chelation initiation in these patients [60]. In NTDT, direct assessment of liver iron concentration, by means of biopsy or magnetic resonance imaging (MRI) analysis every 1-2 years is recommended. MRI analysis has become the mainstay of treatment, as it very accurate and less invasive. In areas where MRI analysis is not readily available, an algorithm that relates serum ferritin to liver iron concentration has been proposed. A decision to initiate chelation therapy should be based on the extent of iron overload and the rate of iron accumulation.
The OPTIMAL CARE study showed that, in NTDT, effective iron chelation can keep serum ferritin levels relatively low, thereby preventing the development of clinical complications due to iron overload [21,61-63]. In addition, NTDT ( $\beta$-thalassaemia intermedia) patients who received transfusion as well as chelation therapy were shown to have a lower incidence of complications compared with patients who received no treatment or either therapy alone [21]. It is therefore evident that, in many NTDT patients, RBC transfusion given in combination with chelation therapy can have considerable short- and long-term benefits. As chelation therapy can counter organ iron loading, which is an important disadvantage of RBC transfusion, NTDT patients can derive more benefits from transfusion-induced improvement of $\mathrm{Hb}$ levels.

\section{Splenectomy}

All NTDT patients, regardless of transfusion pattern, experience an increase in spleen volume over time [16]. This, in turn, causes a worsening of anaemia and consequently, an increased demand for RBC transfusion $[1,2,16]$. Patients with hypersplenism may also experience leucopoenia and thrombocytopenia, which can lead to recurrent bacterial infection or bleeding. In severe cases, patients develop splenomegaly, which is accompanied by symptoms such as left upper quadrant pain and early satiety. These patients are at risk of developing splenic rupture.

A decision to splenectomize an NTDT patient is complex as there is evidence that in these patients, splenectomy can increase the risk of complications such as thromboembolic events and infection [64]. Results from the OPTIMAL CARE study showed that in patients with NTDT, there is an independent association between splenectomy and an increase in the occurrence of thromboembolism, PHT, heart failure, iron-related endocrinopathy and leg ulcers [21]. Splenectomy is also known to increase the risk of infection, which, in turn, has a high risk for mortality, especially in young patients $[65,66]$. However, splenectomy with appropriate preventive measures including vaccination and antibiotic prophylaxis is still recommended for patients with $\mathrm{HbH}$ disease who almost always respond to this treatment modality and rarely require further blood transfusions [44].

\section{Early detection of NTDT: the role of the family physician}

An algorithm is presented in Figure 3 to outline the role of the family (or primary) physician in identification and management of NTDT patients. Family physicians are usually the first point-of-contact with patients and therefore an understanding of NTDT presentation will help to facilitate quick diagnosis and appropriate referral. Patients with NTDT require specialist care for long-term management, 


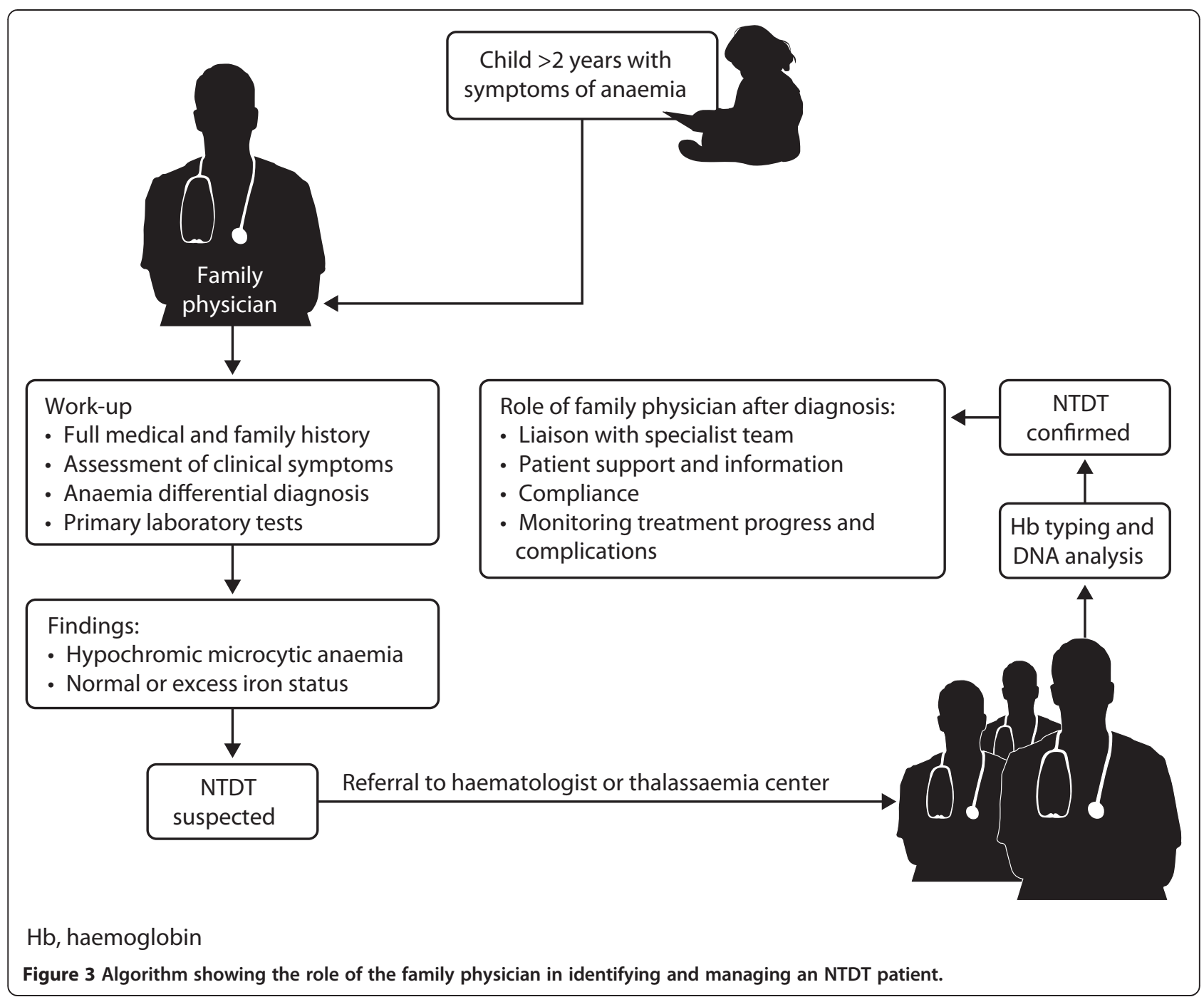

and should therefore be referred to a haematologist or specialist thalassaemia centre (where available) immediately after diagnosis. Even though the patient's treatment will be managed by a specialist, awareness of ongoing NTDT therapy is important when prescribing treatment for nonNTDT related medical problems and encouraging patients to remain compliant with their treatment plan. In addition, the patient or family member might come to the family physician for advice and information about NTDT. A healthy lifestyle should be encouraged and patients should avoid smoking, prolonged immobilization and oral contraceptives. For patients with a history of thrombosis, aspirin might be beneficial. Tea consumption should be encouraged in NTDT patients, as it may have some benefit in decreasing iron absorption from the gut [42].

\section{Conclusion}

NTDT is a recently introduced term used to describe thalassaemia phenotypes that do not depend on regular blood transfusions for survival and daily function. The case study described at the beginning of our review illustrates how NTDT patients can present in a family medical practice. Patients with NTDT develop unique combination of clinical complications because they suffer from chronic anaemia, ineffective erythropoiesis and increased iron absorption through the GIT. The recent advances in our understanding of the thalassaemia types and the clinical complications associated with NTDT have made it possible to improve the longterm management of these patients. A timely diagnosis of NTDT can considerably improve outcomes, and all patients who present with anaemia should have appropriate laboratory blood analyses, including full blood counts and blood smears. A diagnosis of microcytic hypochromic anaemia requires further investigation by means of $\mathrm{Hb}$ analysis by HPLC or electrophoresis. In addition, DNA analysis is necessary to determine the exact thalassaemia disorder, especially for patients with 
$\alpha$-thalassaemia syndromes. Patients with NTDT require specialist care for long-term management. Therapeutic approaches can include intermittent blood transfusion, $\mathrm{HU}$ administration and iron chelation therapy.

\section{Endnote}

${ }^{1}$ Chem-10 includes: BUN (Blood urea nitrogen); CA (Calcium); Na (Sodium); K (Potassium); Cl (Chloride); $\mathrm{CO} 2$ (Bicarbonate); Creatinine; Glucose; Phosphorus; GGT (Gamma-glutamyl transpeptidase).

\section{Abbreviations \\ CBC: Complete blood count; CS: Constant spring; EPO: Erythropoietin GIT: Gastrointestinal tract; Hb: Haemoglobin; HbPS: Hb Paksé; HPLC: High-pressure liquid chromatography; HU: Hydroxyurea; MCH: Mean corpuscular haemoglobin; MCHC: Mean corpuscular haemoglobin concentration; MCV: Mean corpuscular volume; MRI: Magnetic resonance imaging; NTDT: Non-transfusion dependent thalassaemia; PHT: Pulmonary hypertension; RBC: Red blood cell; TDT: Transfusion-dependent thalassaemia; TI: Beta-thalassaemia intermedia; TM: Thalassaemia major.}

\section{Competing interests}

$\checkmark$ Viprakasit received research grant support and lecture fees from Novartis Pharmaceuticals and research grant support from GPO-L-ONE, Thailand, FerroKin Biosciences and National Research University (NRU), Thailand; Dr AT Taher received research funding and honoraria from Novartis Pharmaceuticals.

\section{Authors' contributions}

All authors contributed to a draft of the manuscript and were subsequently involved in revising the manuscript critically for important intellectual content. All authors read and approved the final manuscript.

\section{Acknowledgments}

Financial support for medical editorial assistance was provided by Novartis Pharmaceuticals. We thank Holly Gilbert-Jones for medical editorial assistance with this manuscript. The authors are fully responsible for the content and editorial decisions for this manuscript.

Received: 27 January 2014 Accepted: 5 August 2014 Published online: 30 September 2014

\section{References}

1. Borgna-Pignatti C: Modern treatment of thalassaemia intermedia. Br J Haematol 2007, 138:291-304.

2. Borgna-Pignatti C, Marsella M, Zanforlin N: The natural history of thalassemia intermedia. Ann N Y Acad Sci 2010, 1202:214-220.

3. Taher AT, Musallam KM, Cappellini MD, Weatherall DJ: Optimal management of beta thalassaemia intermedia. Br J Haematol 2011, 152:512-523.

4. Weatherall $D J$ : The definition and epidemiology of non-transfusion-dependent thalassemia. Blood Rev 2012, 26(Suppl 1):S3-S6.

5. Galanello R, Origa R: Beta-thalassemia. Orphanet J Rare Dis 2010, 5:11.

6. Harteveld CL, Higgs DR: Alpha-thalassaemia. Orphanet J Rare Dis 2010, 5:13.

7. Muncie HL Jr, Campbell J: Alpha and beta thalassemia. Am Fam Physician 2009, 80:339-344.

8. Higgs DR, Thein SL, Wood WG: Distribution and population genetics of the thalassaemias. In The Thalassemia Syndromes. Edited by Weatherall DJ, Clegg JB. London: Blackwell Science, Ltd; 2001:237-284.

9. Patrinos GP, Giardine B, Riemer C, Miller W, Chui DH, Anagnou NP, Wajcman $H$, Hardison RC: Improvements in the HbVar database of human hemoglobin variants and thalassemia mutations for population and sequence variation studies. Nucleic Acids Res 2004, 32:D537-D541.

10. Viprakasit V, Lee-Lee C, Chong QT, Lin KH, Khuhapinant A: Iron chelation therapy in the management of thalassemia: the Asian perspectives. Int J Hematol 2009, 90:435-445.

11. Weatherall and Clegg: Inherited haemoglobin disorders: an increasing global health problem. Bull World Health Organ 2001, 79:704-712.
12. Weatherall $D J$ : The inherited diseases of hemoglobin are an emerging global health burden. Blood 2010, 115:4331-4336.

13. Weatherall DJ: Genetic variation and susceptibility to infection: the red cell and malaria. Br J Haematol 2008, 141:276-286.

14. Galanello R, Cao A: Relationship between genotype and phenotype: thalassemia intermedia. Ann N Y Acad Sci 1998, 850:325-333.

15. Thein SL: Genetic insights into the clinical diversity of beta thalassaemia. Br J Haematol 2004, 124:264-274.

16. Fucharoen S, Ketvichit P, Pootrakul P, Siritanaratkul N, Piankijagum A, Wasi P: Clinical manifestation of beta-thalassemia/hemoglobin $E$ disease. J Pediatr Hematol Oncol 2000, 22:552-557.

17. Lai ME, Vacquer S, Carta MP, Spiga A, Cocco P, Angius F, Mandas A, Dessi S: Thalassemia intermedia is associated with a proatherogenic biochemical phenotype. Blood Cells Mol Dis 2011, 46:294-299.

18. Lal A, Goldrich ML, Haines DA, Azimi M, Singer ST, Vichinsky EP: Heterogeneity of hemoglobin $\mathrm{H}$ disease in childhood. N Eng/ J Med 2011, 364:710-718.

19. Musallam KM, Taher AT, Rachmilewitz EA: Beta-thalassemia intermedia: a clinical perspective. Cold Spring Harb Perspect Med 2012, 2:a013482.

20. Taher A, Isma'eel H, Cappellini MD: Thalassemia intermedia: revisited. Blood Cells Mol Dis 2006, 37:12-20.

21. Taher AT, Musallam KM, Karimi M, El-Beshlawy A, Belhoul K, Daar S, Saned MS, El-Chafic AH, Fasulo MR, Cappellini MD: Overview on practices in thalassemia intermedia management aiming for lowering complication rates across a region of endemicity: the OPTIMAL CARE study. Blood 2010, 115:1886-1892.

22. Rivella S: The role of ineffective erythropoiesis in non-transfusion dependent thalassemia. Blood Rev 2012, 26(Suppl 1):S12-S15.

23. Rivella S: Ineffective erythropoiesis and thalassemias. Curr Opin Hematol 2009, 16:187-194.

24. Olivieri NF, Weatherall DJ: Clinical aspects of B-thalassemia. In Disorders of Hemoglobin: Genetics, Pathophysiology, and Clinical Management. Edited by Steinberg MH, Forget BG, Higgs DR, Weatherall DJ. Cambridge: Cambridge University Press; 2009.

25. Olivieri NF: The beta-thalassemias. N Engl J Med 1999, 341:99-109.

26. Taher AT, Musallam KM, El-Beshlawy A, Karimi M, Daar S, Belhoul K, Saned MS, Graziadei G, Cappellini MD: Age-related complications in treatmentnaive patients with thalassaemia intermedia. Br J Haematol 2010, 150:486-489.

27. Doulgeraki A, Athanasopoulou H, Voskaki I, Tzagaraki A, Karabatsos F, Fragodimitri C, Georgakopoulou E, lousef J, Monopolis I, Chatziliami A, Karagiorga M: Bone health evaluation of children and adolescents with homozygous beta-thalassemia: implications for practice. J Pediatr Hematol Oncol 2012, 34:344-348.

28. Pirinccioglu AG, Akpolat V, Koksal O, Haspolat K, Soker M: Bone mineral density in children with beta-thalassemia major in Diyarbakir. Bone 2011, 49:819-823.

29. Vogiatzi MG, Macklin EA, Fung EB, Cheung AM, Vichinsky E, Olivieri N, Kirby M, Kwiatkowski JL, Cunningham M, Holm IA, Lane J, Schneider R, Fleisher M, Grady RW, Peterson CC, Giardina PJ: Bone disease in thalassemia: a frequent and still unresolved problem. J Bone Miner Res 2009, 24:543-557.

30. Pippard MJ, Callender ST, Warner GT, Weatherall DJ: Iron absorption and loading in beta-thalassaemia intermedia. Lancet 1979, 2:819-821.

31. Pootrakul P, Kitcharoen K, Yansukon P, Wasi P, Fucharoen S, Charoenlarp P, Brittenham G, Pippard MJ, Finch CA: The effect of erythroid hyperplasia on iron balance. Blood 1988, 71:1124-1129.

32. Tanno T, Miller JL: Iron loading and overloading due to ineffective erythropoiesis. Adv Hematol 2010, 2010:358283.

33. Taher A, Isma'eel H, Mehio G, Bignamini D, Kattamis A, Rachmilewitz EA, Cappellini MD: Prevalence of thromboembolic events among 8,860 patients with thalassaemia major and intermedia in the Mediterranean area and Iran. Thromb Haemost 2006, 96:488-491.

34. Taher AT, Musallam KM, Karimi M, El-Beshlawy A, Belhoul K, Daar S, Saned M, Cesaretti C, Cappellini MD: Splenectomy and thrombosis: the case of thalassemia intermedia. J Thromb Haemost 2010, 8:2152-2158.

35. Viprakasit V, Tanphaichitr VS, Chinchang W, Sangkla P, Weiss MJ, Higgs DR: Evaluation of alpha hemoglobin stabilizing protein (AHSP) as a genetic modifier in patients with beta thalassemia. Blood 2004, 103:3296-3299.

36. Laosombat V, Viprakasit V, Chotsampancharoen T, Wongchanchailert M, Khodchawan S, Chinchang W, Sattayasevana B: Clinical features and molecular analysis in Thai patients with $\mathrm{HbH}$ disease. Ann Hematol 2009, 88:1185-1192. 
37. Fucharoen S, Viprakasit $\mathrm{V}: \mathrm{Hb} \mathrm{H}$ disease: clinical course and disease modifiers. Hematology Am Soc Hematol Educ Program 2009:26-34.

38. Olivieri NF: Treatment strategies for hemoglobin E beta-thalassemia. Blood Rev 2012, 26(Suppl 1):S28-S30.

39. Viprakasit V, Tanphaichitr VS, Mahasandana C, Assteerawatt A, Suwantol L, Veerakul G, Kankirawatana S, Pung-Amritt P, Suvatte V: Linear growth in homozygous beta-thalassemia and beta-thalassemia/hemoglobin $\mathrm{E}$ patients under different treatment regimens. J Med Assoc Thai 2001, 84:929-941.

40. Yin $X L$, Zhang $X H$, Wu ZK, Zhao DH, Zhou YL, Yu YH, Liu TN, Fang SP, Zhou $\mathrm{TH}$, Wang L, Huang J: Pulmonary hypertension risk in patients with hemoglobin $\mathrm{H}$ disease: low incidence and absence of correlation with splenectomy. Acta Haematol 2013, 130:153-159.

41. Viprakasit V, Sawathiparnich P, Sangpraypanm T, Weerakulwattana L, Kiattisakthavee P, Chaichanwatanakul K, Vatana N: Osteopenia is commonly present in prepubertal children with severe $\mathrm{Hb}$ E/thalassemia despite adequate transfusion and iron chelation therapy. ASH Annual Meeting Abstracts 2007, 110:3830.

42. Taher A, Vichinsky E, Musallam KM, Cappellini MD, Viprakasit V: Guidelines for the Management of Non Transfusion Dependent Thalassaemia (NTDT). Thalassemia International Federation: Nicosia; 2013

43. Tso SC, Loh TT, Todd D: Iron overload in patients with haemoglobin H disease. Scand J Haematol 1984, 32:391-394.

44. Viprakasit $\mathrm{V}$ : Alpha thalassemia syndromes: from clinical and molecular diagnosis to bedside management. EHA Hematol Educ Program 2013 7:329-338.

45. Musallam KM, Rivella S, Vichinsky E, Rachmilewitz EA: Non-transfusion-dependent thalassemias. Haematologica 2013, 98:833-844.

46. Guidelines for investigation of the alpha and beta thalassaemia traits: The thalassaemia working party of the BCSH general haematology task force. J Clin Pathol 1994, 47:289-295.

47. British Committee for Standards in Haematology Working Party of the General Haematology Task Force: The laboratory diagnosis of haemoglobinopathies. Br J Haematol 1998, 101:783-792.

48. Fucharoen G, Sanchaisuriya K, Sae-ung N, Dangwibul S, Fucharoen S: A simplified screening strategy for thalassaemia and haemoglobin $\mathrm{E}$ in rural communities in south-east Asia. Bull World Health Organ 2004, 82:364-372.

49. O'Riordan S, Hien TT, Miles K, Allen A, Quyen NN, Hung NQ, Anh DQ, Tuyen LN, Khoa DB, Thai CQ, Triet DM, Phu NH, Dunstan S, Peto T, Clegg J, Farrar J, Weatherall D: Large scale screening for haemoglobin disorders in southern Vietnam: implications for avoidance and management. Br J Haematol 2010, 150:359-364.

50. Taher AT, Musallam KM, Nasreddine W, Hourani R, Inati A, Beydoun A: Asymptomatic brain magnetic resonance imaging abnormalities in splenectomized adults with thalassemia intermedia. J Thromb Haemost 2010, 8:54-59.

51. Musallam KM, Khoury B, Bi-Habib R, Bazzi L, Succar J, Halawi R, Hankir A Koussa S, Taher AT: Health-related quality of life in adults with transfusionindependent thalassaemia intermedia compared to regularly transfused thalassaemia major: new insights. Eur J Haematol 2011, 87:73-79.

52. Taher A, Hershko C, Cappellini MD: Iron overload in thalassaemia intermedia: reassessment of iron chelation strategies. Br J Haematol 2009, 147:634-640.

53. Dixit A, Chatterjee TC, Mishra P, Choudhry DR, Mahapatra M, Tyagi S, Kabra $M$, Saxena R, Choudhry VP: Hydroxyurea in thalassemia intermedia-a promising therapy. Ann Hematol 2005, 84:441-446.

54. Karimi M, Darzi H, Yavarian M: Hematologic and clinical responses of thalassemia intermedia patients to hydroxyurea during 6 years of therapy in Iran. J Pediatr Hematol Oncol 2005, 27:380-385.

55. Singer ST, Kuypers FA, Olivieri NF, Weatherall DJ, Mignacca R, Coates TD, Davies S, Sweeters N, Vichinsky EP: Fetal haemoglobin augmentation in E/beta (0) thalassaemia: clinical and haematological outcome. BrJ Haematol 2005, 131:378-388.

56. Ansari SH, Shamsi TS, Munzir S, Khan MT, Erum S, Perveen K, Farzana T, Ashraf M, Mehboob T, Moinuddin M: Ggamma-Xmn I polymorphism: a significant determinant of beta-thalassemia treatment without blood transfusion. J Pediatr Hematol Oncol 2013, 35:e153-e156.

57. Sharma N, Das R, Kaur J, Ahluwalia J, Trehan A, Bansal D, Panigrahi I, Marwaha RK: Evaluation of the genetic basis of phenotypic heterogeneity in north Indian patients with thalassemia major. Eur J Haematol 2010, 84:531-537.
58. Taher A, El Rassi F, Isma'eel H, Koussa S, Inati A, Cappellini MD: Correlation of liver iron concentration determined by R2 magnetic resonance imaging with serum ferritin in patients with thalassemia intermedia. Haematologica 2008, 93:1584-1586.

59. Taher AT, Musallam KM, Wood JC, Cappellini MD: Magnetic resonance evaluation of hepatic and myocardial iron deposition in transfusion-independent thalassemia intermedia compared to regularly transfused thalassemia major patients. Am J Hematol 2010, 85:288-290

60. Taher AT, Viprakasit V, Musallam KM, Cappellini MD: Treating iron overload in patients with non-transfusion-dependent thalassemia. Am J Hematol 2013, 88:409-415.

61. Ladis V, Berdousi $H$, Gotsis $E$, Kattamis A: Deferasirox administration for the treatment of non-transfusional iron overload in patients with thalassaemia intermedia. Br J Haematol 2010, 151:504-508.

62. Pootrakul P, Sirankapracha P, Sankote J, Kachintorn U, Maungsub W, Sriphen K, Thakernpol K, Atisuk K, Fucharoen S, Chantraluksri U, Shalev O, Hoffbrand AV: Clinical trial of deferiprone iron chelation therapy in beta-thalassaemia/ haemoglobin E patients in Thailand. Br J Haematol 2003, 122:305-310.

63. Taher AT, Porter J, Viprakasit V, Kattamis A, Chuncharunee S, Sutcharitchan P, Siritanaratkul N, Galanello R, Karakas Z, Lawniczek T, Ros J, Zhang Y, Habr D, Cappellini MD: Deferasirox reduces iron overload significantly in nontransfusion-dependent thalassemia: 1-year results from a prospective, randomized, double-blind, placebo-controlled study. Blood 2012, 120:970-977.

64. Cappellini MD, Robbiolo L, Bottasso BM, Coppola R, Fiorelli G, Mannucci AP: Venous thromboembolism and hypercoagulability in splenectomized patients with thalassaemia intermedia. Br J Haematol 2000, 111:467-473.

65. Bisharat N, Omari H, Lavi I, Raz R: Risk of infection and death among post-splenectomy patients. J Infect 2001, 43:182-186.

66. Olivieri NF, Muraca GM, O'Donnell A, Premawardhena A, Fisher C, Weatherall DJ: Studies in haemoglobin E beta-thalassaemia. Br J Haematol 2008, 141:388-397.

doi:10.1186/s13023-014-0131-7

Cite this article as: Viprakasit et al:: Identification and key management of non-transfusion-dependent thalassaemia patients: not a rare but potentially under-recognised condition. Orphanet Journal of Rare Diseases 2014 9:131.

\section{Submit your next manuscript to BioMed Central and take full advantage of:}

- Convenient online submission

- Thorough peer review

- No space constraints or color figure charges

- Immediate publication on acceptance

- Inclusion in PubMed, CAS, Scopus and Google Scholar

- Research which is freely available for redistribution

Submit your manuscript at www.biomedcentral.com/submit
C Biomed Central 